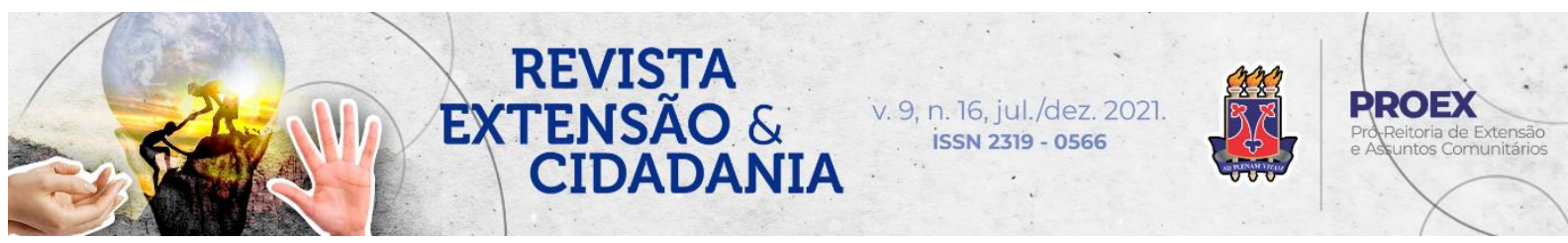

DOI: $10.22481 /$ recuesb.v9i16.9569

\title{
RELATO DE EXPERIÊNCIA: DIREITOS HUMANOS E JUSTIÇA "ENREDANDO SABERES: IMPASSES DA PRÁTICA": O TRABALHO EM REDE NA SOCIOEDUCAÇÃO
}

\section{"ENGAGING KNOWLEDGE: IMPASSES IN PRACTICE": NETWORKING IN SOCIO- EDUCATION}

\section{"INVOLUCRAR EL CONOCIMIENTO: IMPASSES EN LA PRÁCTICA": TRABAJO EN RED EN SOCIOEDUCACIÓN}

Lucia Maria de Freitas Perez ${ }^{1}$

Andréa Martello ${ }^{2}$

Samia Jraige ${ }^{3}$

Marlise Eugenie D'Icarahy ${ }^{4}$

Laura de Sousa Ferreira Brito 5

Yasmim Cristina dos Santos Nascimento ${ }^{6}$

Resumo: Este escrito se propõe a tecer um relato das experiências vivenciadas durante a execução do projeto "Em nome do Sujeito: encontros de psicanálise, educação, literatura e artes", um dos braços do Programa de extensão "Enredando Saberes: impasses da prática", da Universidade Federal do Estado do Rio de Janeiro (UNIRIO). Tal projeto, em parceria com o Serviço de Psicologia da Vara de Execução de Medidas Socioeducativas do Rio de Janeiro

\footnotetext{
${ }^{1}$ Psicóloga. Doutora em Psiquiatria, Psicanálise e Saúde Mental, pela Universidade Federal do Rio de Janeiro. Professora Associada do Departamento de Fundamentos da Educação da Universidade Federal do Estado do Rio de Janeiro (UNIRIO). Rio de Janeiro, Brasil. Orcid: https://orcid.org/0000-0002-5244-7926 E-mail: luciafreitasperez@gmail.com

${ }^{2}$ Psicóloga. Doutora em Teoria Psicanalítica, pela Universidade Federal do Rio de Janeiro. Professora Adjunta da Escola de Educação da Universidade Federal do Estado do Rio de Janeiro (UNIRIO). Rio de Janeiro, Brasil. Orcid: https://orcid.org/0000-0002-8000-8138Ｅ-mail: demartello@gmail.com

${ }^{3}$ Museóloga. Mestra em Ciências Sociais, pela Universidade do Estado do Rio de Janeiro. Integrante do Programa de extensão "Enredando saberes: impasses da prática" da Universidade Federal do Estado do Rio de Janeiro (UNIRIO). Rio de Janeiro, Brasil. Orcid: https://orcid.org/0000-0001-7599-7974 E-mail: samia.jraige@gmail.com

${ }^{4}$ Psicóloga. Doutora em Teoria e Clínica Psicanalítica, pela Universidade do Estado do Rio de Janeiro (UNIRIO) e em Psicologia pela Universidade Nice Sophia Antipólis, atual Université Côte D’Azur. Rio de Janeiro, Brasil. Orcid: https://orcid.org/0000-0003-4221-3066 E-mail: marliseeugenie@ gmail.com

${ }^{5}$ Graduanda em Pedagogia, pela Universidade Federal do Estado do Rio de Janeiro (UNIRIO). Rio de Janeiro, Brasil. Orcid: https://orcid.org/0000-0002-3128 E-mail: britosousalaura@gmail.com

${ }^{6}$ Graduanda em Direito, pela Universidade Federal do Rio de Janeiro (UNIRIO). Rio de Janeiro, Brasil. Orcid: https://orcid.org/0000-0002-5419-4993Ｅ-mail: cristinasantoscd361@gmail.com
} 
(VEMSE/RJ), compôs, desde 2018, o programa interinstitucional "Eu apoio a voz do adolescente", que enlaçando a universidade, o judiciário e setores educativos de três diferentes museus - Museu da ALERJ, Museu da Justiça e Museu Histórico Nacional - fomentou novas estratégias de atendimento e acolhimento aos adolescentes em cumprimento de medidas socioeducativas que, atentas às dimensões psicológica, cultural, política, pedagógica e jurídica, contribuíram para a integração desses jovens na dimensão simbólica de seu tempo, a partir da promoção de uma elaboração de seu lugar na cidade.

Palavras-chave: Programa de extensão. Socioeducação. Psicanálise. Atividades culturais. Museus.

Abstract: This paper proposes to weave an account of the experiences lived during the execution of the project "In the name of the Subject: meetings of psychoanalysis, education, literature and arts", one of the arms of the extension program "Engaging Knowledge: impasses of practice", of the Federal University of the State of Rio de Janeiro (UNIRIO). This project, in partnership with the Psychology Service of the Socio-educational Measures Execution Court of Rio de Janeiro (VEMSE/RJ), has composed, since 2018, the inter-institutional program "I support the voice of the adolescent", which links the university, the judiciary and educational sectors of three different museums - ALERJ Museum, Justice Museum and National Historical Museum - promoted new strategies for assisting and welcoming adolescents in compliance with socio-educational measures that, attentive to the psychological, cultural, political, pedagogical and legal dimensions, contributed for the integration of these young people in the symbolic dimension of their time, from the promotion of an elaboration of their place in the city.

Keywords: Extension program. Socioeducation. Cultural activities. Museums.

Resumen: Este artículo propone tejer un relato de las experiencias vividas durante la ejecución del proyecto "En nombre del Sujeto: encuentros de psicoanálisis, educación, literatura y artes", uno de los brazos del programa de extensión "Engaging Knowledge: impasses of práctica ", de la Universidad Federal del Estado de Rio de Janeiro (UNIRIO). Este proyecto, en alianza con el Servicio de Psicología del Juzgado de Ejecución de Medidas Socioeducativas de Rio de Janeiro (VEMSE/RJ), ha compuesto, desde 2018, el programa interinstitucional "Apoyo la voz del adolescente", que vincula al Los sectores universitario, judicial y educativo de tres museos diferentes - Museo ALERJ, Museo de la Justicia y Museo Histórico Nacional impulsaron nuevas estrategias de atención y acogida de adolescentes en el cumplimiento de medidas socioeducativas que, atentas a los aspectos psicológicos, culturales, políticos, pedagógicos y dimensiones legales, contribuyeron para la integración de estos jóvenes en la dimensión simbólica de su tiempo, a partir de la promoción de una elaboración de su lugar en la ciudad.

Palabras clave: Programa de extensión. Socioeducación. Actividades culturales. Museos.

Revista Extensão \& Cidadania, v. 9, n. 16, p. 300-313, jul./dez. 2021. 


\section{Introdução}

Por que não estabelecer uma necessária "intimidade" entre os saberes curriculares fundamentais aos alunos e a experiência social que eles têm como indivíduos?

Paulo Freire

Este trabalho consiste em apresentar, em forma de relato de experiência, um pouco da história, da proposta, da dinâmica e das questões suscitadas e trabalhadas de maneira coletiva pelos integrantes do projeto extensionista "Em nome do sujeito: encontros de psicanálise, educação, literatura e artes”. Desde sua origem, em 2016, o projeto visou, através da valorização da psicanálise, da literatura e das artes em geral, produzir no cotidiano de diferentes espaços institucionais, intervalos que pudessem favorecer a emergência do sujeito e de sua singular sensibilidade. Em meados de 2017 e ao longo de 2018, este projeto que compõe o Programa "Enredando saberes, impasses da prática", da Pró-Reitoria de Extensão e Cultura da Universidade Federal do Estado do Rio de Janeiro (PROEXC/UNIRIO) voltou-se para a socioeducação, a partir do estabelecimento de parceria com Serviço de Psicologia da Vara de Execução de Medidas Socioeducativas (VEMSE). Giro que nos pareceu fundamental por colocar em trabalho impasses históricos, dos quais destacamos o "racismo estrutural" (ALMEIDA, 2018), entendendo que a história do Brasil traz marcas de um processo de colonização perverso, fruto de uma tradição colonialista escravocrata e que se reflete na forma preconceituosa pela qual a sociedade ainda segrega e criminaliza a juventude pobre e negra.

Reconhecemos que no âmbito legal esforços já vinham sendo feitos no sentido de destacar e proteger esse grupo, entendendo-os como pessoas ainda em desenvolvimento e que culminaram, em 1990, na promulgação da Lei Federal n 8.069, Estatuto da Criança e do Adolescente (ECA) (BRASIL, 1990). Lei que ratifica o direito da população infanto-juvenil à proteção integral já conferida pela Constituição Federal de 1988 (BRASIL, 1988), conferindo aos adolescentes o direito de um pleno desenvolvimento físico, biológico, psicológico e cognitivo. De acordo com o ECA (BRASIL, 1990), adolescentes de até 18 anos, que cometam atos infracionais, devem cumprir medidas socioeducativas, não apenas para reparar estes atos perante a sociedade, mas para, através de um trabalho educativo, serem reintegrados à sociedade. Entretanto, embora mais de 30 anos tenham decorrido, desde a promulgação da lei, boa parte das conquistas ali preconizadas ainda não se efetivaram no cotidiano da realidade

Revista Extensão \& Cidadania, v. 9, n. 16, p. 300-313, jul./dez. 2021. 
brasileira. Muitas transformações se fazem ainda necessárias, especialmente no que tange ao tratamento conferido à juventude negra e pobre, predominante no sistema socioeducativo do Estado do Rio de Janeiro (MENDES; JULIÃO, 2018). Assim, por colocar em trabalho tais impasses e apostando, como Lacan (1998), que o psicanalista pode e deve estender sua ação e seu campo de reflexão para as questões de seu tempo, consideramos promissora a parceria estabelecida entre o programa de extensão desenvolvido no âmbito de nossa universidade e o Setor de Psicologia da Vara de Execução de Medidas Socioeducativas. Esse convênio foi formalizado no Diário Oficial da União, em 28 de janeiro de 2018, e originou o Programa Interinstitucional "Eu apoio a voz do adolescente" (TRIBUNAL DA JUSTIÇA, 2018). Tal programa é voltado para o planejamento e execução de ações de promoção de uma escuta direcionada aos adolescentes em cumprimento de medidas socioeducativas, na tentativa de se fazer avançar alguns desses imperativos.

A participação de um coletivo de professoras de Psicologia da Universidade Federal do Estado do Rio de Janeiro (UNIRIO), todas psicanalistas e de seus alunos de diversos cursos, bem como dos setores educativos do Museu da Justiça - Centro Cultural do Poder Judiciário (CCMJ), do Museu Histórico Nacional (MHN) e do Palácio Tiradentes da Assembleia Legislativa do Rio de Janeiro (ALERJ), em colaboração com a única psicóloga lotada na VEMSE, foi fundamental. A partir do trabalho dessa rede interinstitucional, houve uma efetiva convocação e valorização da palavra desses jovens e de suas famílias que, nas diferentes atividades propostas concebidas pelo Programa, tiveram oportunidade de se interrogar acerca de sua efetiva participação nos espaços públicos da cidade. Através da circulação da palavra, alguns desses adolescentes, bem como seus familiares e diferentes atores de seus processos socioeducativos, revisitaram seus percursos e foram convocados a elaborar suas experiências, a partir de seu desejo - dentre todos, o principal material necessário à construção de alternativas diferenciadas para suas existências. A metodologia adotada, calcada na ética da psicanálise (PEREZ; D'ICARAHY; BARROS; MARTELLO, 2019), contribuiu para subverter o lugar por eles ocupado na cena pública: passaram de meros objetos sobre os quais recaiam sanções e medidas punitivas, para sujeitos que, de alguma forma, puderam se implicar em suas histórias e trajetórias.

Em execução desde 2018, o projeto passou por várias fases, atingindo aproximadamente 200 jovens em cumprimento de diferentes medidas socioeducativas, além de seus familiares.

Revista Extensão \& Cidadania, v. 9, n. 16, p. 300-313, jul./dez. 2021. 
Entre suas ações, destacam-se as visitas mediadas realizadas em museus e centros culturais, ações educativas, esquetes teatrais, e dramatizações, sempre acompanhadas de rodas de conversas, nas quais os adolescentes produziram elaborações acerca da experiência na socioeducação e nas atividades realizadas no projeto. Essas elaborações foram registradas em documentos individuais, denominados por nós como "A voz do adolescente", que, quando autorizados pelos autores, puderam ser anexados aos seus autos processuais, fazendo reverberar a voz e a perspectiva desses jovens no espaço jurídico. A seguir, descrevemos as diferentes etapas do projeto, ao longo dos últimos anos, e a especificidade do trabalho realizado em parceria com os museus e instituições culturais.

\section{Ano de 2018: Adolescentes em Liberdade Assistida}

Por uma questão de facilidade estratégica e de logística, inicialmente, direcionamos nosso olhar para os adolescentes em cumprimento da medida Liberdade Assistida, prevista no art. 112, inciso IV, do ECA (BRASIL, 1990). Quando em cumprimento dessa medida, mais branda que as demais e que faculta aos adolescentes à livre circulação pela cidade, tais jovens eram convidados pela Vara a participar das ações propostas por nosso programa interinstitucional. Esses convites eram encaminhados pelo Centro de Referência Especializado de Assistência Social (CREAS), que se incumbia de reuni-los, providenciando o transporte que os conduziria até o Centro do Rio, local onde se situa o setor de Psicologia da VEMSE, ponto de origem e finalização de nossos circuitos.

As rodas de conversa e visitas aos museus abriram aos adolescentes a possibilidade de expressar suas perspectivas, enquanto sujeitos e cidadãos que passaram pela experiência da socioeducação. No processo de elaboração, ocorrido ao longo das visitas e das rodas, discutiamse questões trazidas por esses jovens, bem como outras introduzidas pelas equipes em parceria. Durante o registro final, eram acompanhados pelos alunos do projeto extensionista e pelos educadores dos espaços culturais que, quando necessário, os assessoravam pedagogicamente, pois alguns desses adolescentes apresentavam dificuldades no letramento, muitos deles não eram alfabetizados. Nesses registros, as formas de expressão adotadas eram as mais variadas e de total livre escolha, como poemas, desenhos, histórias, colagens, cartas e textos. Ao fim, eram convidados pela equipe a compartilhar e a anexar esses registros em seus autos processuais.

Revista Extensão \& Cidadania, v. 9, n. 16, p. 300-313, jul./dez. 2021. 


\section{Ano de 2019: Adolescentes em Internação Domiciliar}

Ao final de 2018, alguns jovens em cumprimento da medida de Internação, por conta da superlotação nas unidades do Departamento Geral de Ações Socioeducativas (DEGASE), receberam, por parte do Ministro Fachin, a determinação de cumprir a excepcional medida de Internação Domiciliar (BRASIL, 2018). Através dessa medida de exceção, alguns jovens, que até então, cumpriam medida em um regime fechado, foram selecionados para experienciar uma nova modalidade, intermediária entre a Internação e a Liberdade Assistida, que poderia ser cumprida em seus lares, porém sem a mesma flexibilidade oferecida aos que cumprem a medida mais branda. Desde que acompanhados por seus pais ou responsáveis, esses jovens, até então totalmente segregados, puderam, no Rio de Janeiro, participar das ações de nosso programa, possibilitando uma abertura para a criação de novas propostas direcionadas a esse novo público. Para além das visitas a museus, introduzimos a apresentação de esquetes teatrais, sempre seguidos pelas rodas de conversas e pela elaboração de registros.

\section{Ano 2020-2021: O que fazer na pandemia?}

Em março de 2020, no retorno às aulas, fomos surpreendidos com a eclosão de uma pandemia (SARS-Covid-19) que ensejou a suspensão das atividades presenciais de ensino, pesquisa e extensão de nossa universidade. Como dar continuidade virtualmente a atividades que têm como traços principais o encontro, a socialização e a livre circulação por espaços culturais? Diante da impossibilidade de acesso direto aos jovens em cumprimento de medidas, durante o isolamento social, temos nos dedicado a preparação de material educativo que possa funcionar como disparador nas sessões individuais e virtuais conduzidas pela psicóloga da Vara, como vinhetas, jingles, pequenos filmes, podcasts, bem como ao estudo sobre a temática, à organização do material coletado durante a experiência e à construção de um site para o Programa.

Revista Extensão \& Cidadania, v. 9, n. 16, p. 300-313, jul./dez. 2021. 


\section{Transitando pelos espaços museais}

A ideia de museu tradicional ainda está muito associada à exposição de uma história oficial e de "verdades" que reforçam o poder já instituído. Percebemos a dificuldade de determinados grupos estarem presentes nesses espaços ainda hoje. Em paralelo, diversas percepções sociais do papel dos museus passam a entrar em disputa, e diferentes públicos passam a interferir em sua dinâmica (VARINE-BOHAN, 1995). Pensando os museus enquanto lugares de memória e o apagamento da memória enquanto prática racista, a presença dos adolescentes da socioeducação é de extrema importância, assim como a existência de iniciativas que atuem como contrapontos, como resistências e até mesmo como subversões nesses espaços. Dessa maneira, aproveitamos os espaços museais e culturais para serem aliados e para atuarem como alternativa dentro das práticas socioeducativas.

Os três museus parceiros do programa, Museu da Justiça, Museu Histórico Nacional e Palácio Tiradentes, da ALERJ, com seus acervos artísticos, históricos e humano e com a atuação de seus educadores e educadoras, tiveram um papel singularíssimo no planejamento e execução de nossas ações, categorizando três roteiros que exigem um lugar especial nesse relato de experiências.

\section{Museu da Justiça - Centro Cultural do Poder Judiciário}

O prédio localizado na Rua Dom Manuel, 29, Centro do Rio de Janeiro, e que hoje abriga tanto o Museu da Justiça - Centro Cultural do Poder Judiciário (CCMJ), como a sala do setor de Psicologia da VEMSE, tinha como finalidade originária ser o endereço da Corte de Apelação, tribunal de última instância do Distrito Federal. Transformado em museu, em 1988, voltou-se à preservação da memória do Poder Judiciário.

Acolhidos inicialmente na sala do setor de Psicologia da VEMSE, os adolescentes participavam de jornadas educativas que começavam por uma leitura do simbolismo em sua arquitetura. Desde a rua, eram convidados a examinar coletivamente a fachada do prédio, adentrando até o interior dos diversos salões, mediados pelas intervenções do setor educativo do museu, que buscavam despertar a curiosidade dos adolescentes pelo espaço. Durante o percurso, discutiam-se, entre outros assuntos, temas referidos aos sentidos que podem ser

Revista Extensão \& Cidadania, v. 9, n. 16, p. 300-313, jul./dez. 2021. 
conferidos à palavra justiça. O momento culminante se dava no Salão do Antigo Tribunal do Júri, quando os adolescentes dramatizavam um ato que narrava, ao modo do júri popular, um processo de julgamento. A dramatização lhes permitia, além de experienciar diferentes papéis, refletir coletivamente sobre as encenações e sobre valores éticos e morais.

O roteiro acima, adotado desde a primeira versão de nossa proposta de trabalho, quando dirigimos nossas ações apenas para os adolescentes em Liberdade Assistida, sofreu uma significativa alteração ao nos dirigirmos, no início de 2019, para aqueles em Internação Domiciliar. Nesse novo formato, o primeiro acolhimento a esse grupo de jovens, acompanhados de seus familiares, também acontecia na sala do Serviço de Psicologia da VEMSE, de onde eram conduzidos à sala multiuso, atualmente um teatro localizado no subsolo do CCMJ. Nesse espaço, assistiam à esquete teatral do grupo KRIADAKI, protagonizada pelos atores Adriano Rodrigues Oliveira (Jacaré) e Edson Sodré, alunos do curso de teatro da UNIRIO e integrantes do Projeto Teatro nas Prisões, vinculado ao programa "Enredando Saberes: impasses da prática".

A temática da peça "Nosso Evangelho", concebida por Sodré, por despertar questões relativas às vulnerabilidades sociais, econômicas e raciais, favoreceu o debate entre todos integrantes do projeto. As rodas de conversas, disparadas pela peça e mediadas pela psicóloga da Vara, pelas docentes e discentes do projeto e pelos representantes das instituições parceiras, mobilizaram memórias, afetos e interrogaram os sentidos tradicionalmente estabelecidos.

Após o desdobramento das discussões suscitadas pela peça, os jovens eram direcionados até a sala do educativo, onde eram realizadas atividades e ações educativas, debates, a partir de objetos mediadores e da visita aos espaços históricos. Em paralelo a estas atividades, voltadas especificamente aos adolescentes, familiares e acompanhantes faziam uma visita pelo museu, conhecendo salas como o Tribunal Pleno e o Tribunal do Júri. Em seguida, discutiam, também em rodas de conversa, a respeito de questões de liberdade e direitos sociais. Nessas conversas, pais e responsáveis traziam seus pontos de vista sobre o tratamento concedido pelos representantes do Estado para com eles e seus filhos, sobrinhos e netos submetidos ao processo socioeducativo, além de suas angústias relativas ao futuro dos adolescentes sob suas guardas.

Revista Extensão \& Cidadania, v. 9, n. 16, p. 300-313, jul./dez. 2021. 


\section{Museu Histórico Nacional}

O Museu Histórico Nacional, situado na Praça Marechal Âncora, s/n - Centro do Rio de Janeiro, foi criado em 1922, com a missão de preservar e divulgar a história do país. A partir das diversas exposições que abriga e do trabalho realizado pelos educadores do espaço, as atividades tinham como objetivo a atualização e revisão crítica das narrativas hegemônicas. Por decisão estratégica, limitamos nosso passeio ao Pátio dos Canhões, ao antigo Arsenal de Guerra, e também a algumas exposições de longa duração, tal como a intitulada "As moedas contam a história", que despertavam maior interesse dos jovens. Durante a visita, debatíamos com os adolescentes sobre questões históricas, correlacionando-as com nossas próprias histórias.

Além de debater aspectos históricos, a ação ofereceria a possibilidade desses jovens acessarem equipamentos culturais e lugares de memória da cidade, até então desconhecidos ou nunca visitados. A partir das reflexões críticas elaboradas coletivamente, muitos desses jovens puderam tomar a palavra, produzindo falas contundentes. Os adolescentes se posicionavam nessas discussões, não como meros espectadores, mas como sujeitos que se situavam no presente, amparados no passado, podendo projetar outros e diferentes futuros. A partir do contato com a historicidade do sistema jurídico brasileiro, pôde-se discutir sobre o teor punitivista que norteia, de forma recorrente, as ações socioeducativas no Brasil.

\section{Palácio Tiradentes - ALERJ}

O Palácio Tiradentes foi construído na antiga Assembleia Legislativa do Rio de Janeiro (ALERJ) que também fora conhecida como "Cadeia Velha", localiza-se na rua Primeiro de Março, s/n, Praça XV, Rio de Janeiro/RJ, e deve seu nome ao fato de ter tido como um de seus prisioneiros Joaquim José da Silva Xavier, Tiradentes, enforcado em praça pública, em abril de 1792. Na atualidade, para os adolescentes em conflito com a lei, ter a oportunidade de conhecer onde foram e são criadas leis, bem como ter contato com o projeto "Parlamento Juvenil", no qual jovens de escola pública são selecionados para participar ativamente na criação de leis que impactam a vida cotidiana de suas comunidades, abriu-lhes novas perspectivas (LUCIUS, 2018). Tais experiências apresentaram-lhes outras formas e possibilidades de atuação e intervenção social, em que poderiam exercer um papel ativo nesta instância de poder.

Revista Extensão \& Cidadania, v. 9, n. 16, p. 300-313, jul./dez. 2021. 
Percorrer junto aos adolescentes às ruas do Centro da cidade, permitiu-nos perceber o modo como éramos confrontados por olhares atravessados, deixando evidente preconceitos e o desconforto em relação às nossas presenças. Na chegada à ALERJ, éramos recebidos pelos estagiários do Setor Cultural, que nos apresentavam à "Casa do povo", às discussões do Plenário, e a outros espaços histórico-culturais abertos à visitação. Finalmente, quando da chegada ao Salão Nobre, debatiam-se temas como os direitos sociais, o acesso à justiça, aos direitos humanos, o ECA, o Código Penal e a visão de cada adolescente a respeito da elaboração e execução de leis. Em uma dessas reuniões, tivemos as presenças de Renata Souza, Deputada Estadual e Presidente da Comissão de Defesa dos Direitos Humanos e Cidadania, e de Mônica Cunha (CASH, 2016), fundadora do Movimento Moleque, uma organização de mães, pelos direitos de adolescentes no Sistema Socioeducativo e seus familiares, contra a redução da maioridade penal, contra a revista vexatória e a favor dos direitos humanos, fundada em dezembro de 2003, no Rio de Janeiro. As duas mulheres expuseram aos presentes a importância do envolvimento da população na articulação política para reivindicar os direitos básicos dos mais vulneráveis e com pouca participação nos espaços de poder.

\section{Considerações finais: efeitos produzidos pela experiência extensionista}

A passagem por essas vivências produziu efeitos não apenas nos adolescentes que cumpriam algum tipo de medida socioeducativa, mas em todos os que, de alguma forma, participaram do processo. Integram o projeto de extensão alunos de diferentes cursos de graduação da UNIRIO, tais como Pedagogia, Biologia, Música, Teatro, Serviço Social, Direito, Medicina, além de voluntários de diferentes áreas como a Museologia e a Filosofia. A coordenação do projeto é exercida de forma colegiada, por professoras de Psicologia, com formação em Psicanálise, enredando diferentes saberes na construção de uma prática mais inclusiva e que faz valer a função do sujeito e de sua diferença.

Nos encontros, nos deparamos com diferentes impasses, entre eles as distintas linguagens utilizadas pelos adolescentes nas visitas aos espaços museais. Como aproximar a linguagem empregada em ambientes formais, como os museus, à linguagem corriqueira dos adolescentes? Gírias e jargões nos deram pistas sobre os conflitos territoriais que envolvem diferentes regiões do Rio de Janeiro. Como, então, promover condições mínimas para possíveis

Revista Extensão \& Cidadania, v. 9, n. 16, p. 300-313, jul./dez. 2021. 
trocas entre grupos reconhecidamente rivais? Muitos dos jovens extensionistas, oriundos de cotas, moradores dos subúrbios e periferias contribuíram para tal aproximação, via identificação com os adolescentes. Naquele ambiente de tamanha estranheza, a presença dos jovens estudantes introduziu, em um primeiro contato, pontos de abertura e familiaridade, que facilitaram uma maior participação dos adolescentes.

Outro desafio que nos foi colocado pela prática perpassa às estratégias de mediação: como mobilizar o desejo e o interesse pela troca simbólica em adolescentes tão alijados desse tipo de experiência cultural, durante atividades em espaços pouco ou nunca frequentados? Essas questões continuam a nos levar a um constante debate e exigem de nós um contínuo trabalho de avaliação e de sensibilidade, em sintonia com as especificidades de cada grupo.

"Há um mais além da técnica, a ética" (PEREZ; D’ICARAHY; BARROS; MARTELLO, 2019, p.161), afirmam as coordenadoras do programa, que do lugar de psicanalistas e professoras universitárias inseridas na pólis, foram responsáveis pela criação, sustentação e fundamentação deste programa interinstitucional. Tal como uma grande teia, segue crescendo mais e mais, constituindo uma rede ampliada, nos transmitindo, em ato, a existência viva de uma "ética do desejo que, transcendendo a qualquer moral pré-concebida, possibilita ao sujeito não ser esmagado pelas violentas forças presentes no contemporâneo que clamam por seu silenciamento" (PEREZ; D'ICARAHY; BARROS; MARTELLO, 2019, p.161).

Marcados por essa ética, afirmamos que o impacto da experiência do projeto "Em nome do sujeito" está sendo de suma importância para a formação acadêmica dos jovens universitários participantes, pois apresenta novos espaços de atuação profissional, como o campo socioeducativo, expandindo a reflexão para uma vivência fora dos muros da universidade. Aproxima os jovens universitários e a própria universidade de outras realidades, contribuindo para que o integrante do projeto extensionista se abra para outras perspectivas e outras formas de escuta. Passamos a "sentir na pele" o quanto os processos históricos se perpetuam, atuando de forma inconsciente, na naturalização e manutenção de formas jurídicas obsoletas, racistas e colonialistas. O trabalho realizado pelo programa interinstitucional valoriza o lugar de fala e a potência da escuta e diferente do que ocorre com as tradicionais instâncias e instituições de poder, se esforça para não estigmatizar as experiências individuais dos

Revista Extensão \& Cidadania, v. 9, n. 16, p. 300-313, jul./dez. 2021. 
aprendizes, mas sim, considerá-las no momento do fazer pedagógico, entendido como um processo de ação, criação e transformação.

Essa experiência ilustra o quanto a voz do adolescente em conflito com a lei, assim como a de outras "minorias", precisa ser ouvida e para isso é necessário que nós, enquanto sociedade, nos disponhamos a ouvi-la. O processo de desenvolvimento de uma escuta na formação de qualquer acadêmico, coloca na práxis a teoria absorvida na universidade, articulando a Psicanálise de Freud e Lacan à Paulo Freire, que em Pedagogia do Oprimido (1968) ou a Pedagogia da Autonomia (1996) nos apresentam teorias que contribuem para a construção de uma prática pedagógica que deslegitima a ação autoritária e cerceadora, defendendo a liberdade dos educandos em exercer sua subjetividade. Assim, apostamos no enredamento de saberes, pois acreditamos, fundamentados nessa experiência que, assim como a Psicanálise, a educação transformadora seja uma forma de intervir no mundo, a fim de fazer emergir a realidade em suas variadas formas.

Por sua parte, a fundamentação psicanalítica, extraída de uma práxis calcada no ensino de Freud e Lacan, permitiu-nos, tocar nos "mistérios do corpo falante", introduzindo uma prática de falação que testemunhamos exercer efeitos sobre o corpo e sobre o sintoma em suas diversas modalidades, destacando-se aqui a dimensão sociopolítica do sofrimento. Queremos crer que através da tessitura da rede simbólica, constituída a partir desse enredamento de saberes e de afetos, tal como o por nós proposto neste Programa, estejamos convocando à fala sujeitos, que vêm sendo tradicionalmente silenciados. Apostamos que o ecoar dessas vozes permita, tanto a seus emissores como àqueles que as escutam, protagonizar a construção de saídas para pontos de impasses, sejam estes particulares ou coletivos, contribuindo para que tradicionais e naturalizadas formas de subjugação humana passem, minimamente, a produzir estranhamento.

Sustentamos que quanto mais e melhor os sujeitos possam falar daquilo que lhes atravessa, maiores serão as possibilidades de transformação nos modos pelos quais o inconsciente, enquanto linguagem, contribui na manutenção e sustentação de formas preconceituosas. Iniciativas como essa procuram oferecer maiores chances aos sujeitos de virem a ocupar novas posições nos laços sociais, não mais assujeitados a uma moral da conformação, mas fazendo valer uma ética que afirma e sustenta um lugar para a diferença, para o novo e para a transformação.

Revista Extensão \& Cidadania, v. 9, n. 16, p. 300-313, jul./dez. 2021. 


\section{Referências}

ALMEIDA, Silvio. Racismo estrutural. Belo Horizonte: Grupo Editorial Letramento, 2018.

BRASIL. Lei no 8.069, de 13 de julho de 1990. Dispõe sobre o Estatuto da Criança e do Adolescente e dá outras providências. Diário Oficial da República Federativa do Brasil, Brasília, DF, 16 jul. 1990. Disponível em: http://www.planalto.gov.br/ccivil_03/LEIS/L8069.htm\#art266. Acesso em: 26 mar. 2021.

BRASIL. Supremo Tribunal Federal. Agravo regimental no Habeas Corpus 143.988. AGTE(s): Todos os Adolescentes Internados na Unidade de Internação Regional Norte. ADV .: Defensor Público-Geral do Estado do Espírito Santo. AGDO.: Superior Tribunal de Justiça. Rel. Ministro Edson Fachin. Brasília, DF, 16 de agosto de 2018. Diário da Justiça Eletrônico, 20 de agosto de 2018. Disponível em: https://www.stf.jus.br/arquivo/djEletronico/DJE_20180817_169.pdf. Acesso em: 27 mar. 2021.

BRASIL. Constituição Federal de 1988. Brasília, DF, 1988.

CASH, Anna. Rede de mães contra a violência do Estado: uma entrevista com Mônica Cunha. RioOnWatch, publicado em 9 mar. 2016. Seção Destaques, Denúncias, Entrevistas e Perfis. Disponível em: http://rioonwatch.org.br/?p=18634. Acesso em: 27 mar. 2021.

FREIRE, Paulo. Pedagogia da autonomia: saberes necessários à prática educativa. 25. ed. São Paulo: Paz e Terra, 1996.

FREIRE, Paulo. Pedagogia do oprimido. São Paulo: Paz e Terra, 1968.

LACAN, Jacques. Escritos. Rio de Janeiro: Jorge Zahar, 1998.

LUCIUS, Leon. Ação traz jovens em Liberdade Assistida à ALERJ. Rio de Janeiro, 6 jun. 2018. Disponível em: http://www.alerj.rj.gov.br/(X(1)S(m4sukk2nom5bnci15mmisngb))/Visualizar/Noticia/43270? AspxAutoDetectCookieSupport=1. Acesso em: 27 mar. 2021.

MENDES, Claudia Lucia Silva; JULIÃO, Elionaldo Fernandes. Trajetórias de vida de jovens em situação de privação de liberdade no Sistema Socioeducativo do Estado do Rio de Janeiro. Rio de Janeiro: Degase, 2018.

PEREZ, Lucia Maria de Freitas; D'ICARAHY, Marlise Eugenie; DE BARROS, Rita Maria Manso; MARTELLO, Andréa. Por uma ética da pólis: psicanálise e política. In: BRANDÃO, Eduardo (org.). Psicanálise e Direito: subversões do sujeito no campo jurídico. Rio de Janeiro: Nau Editora, 2019.

TRIBUNAL DA JUSTIÇA. TJ do Rio inaugura serviço de psicologia para adolescentes. Rio de Janeiro, 4 jun. 2018. Disponível em: http://www.tjrj.jus.br/noticias/noticia/-/visualizarconteudo/5111210/5569938. Acesso em: 27 mar. 2021.

Revista Extensão \& Cidadania, v. 9, n. 16, p. 300-313, jul./dez. 2021. 
VARINE-BOHAN, Hugues. A respeito da mesa redonda de Santiago do Chile (1972). 1995. Disponível em:

https://edisciplinas.usp.br/pluginfile.php/3832560/mod_resource/content/1/HUGUES\%20DE \%20VARINE.pdf. Acesso em: 1 nov. 2021.

Recebido: 30.09.2021

Aceito: 15.11 .2021

c) (†)

This work is licensed under a Creative Commons Attribution 4.0 International License.

(c) (7)

Este trabalho está licenciado com uma Licença Creative Commons - Atribuição 4.0

Internacional.

Revista Extensão \& Cidadania, v. 9, n. 16, p. 300-313, jul./dez. 2021.

ISSN 2319-0566 DOI: 10.22481/recuesb.v9i16.9569 